\title{
Relação entre Clima Organizacional, Percepção de Mudança Organizacional e Satisfação do Cliente ${ }^{1}$
}

\author{
Juliana Neves Santos ${ }^{2}$ \\ Elaine Rabelo Neiva \\ Universidade de Brasília \\ Eleuni Antônio Andrade-Melo \\ Fundação Universa
}

\begin{abstract}
RESUMO - Este trabalho tem como objeto de estudo as relações entre clima organizacional, percepção de mudança e satisfação do cliente em 170 unidades de uma organização pública prestadora de serviços com atuação em todo o Brasil. Foram analisados dados primários e secundários, agregados em nível de unidade, utilizando-se da técnica de modelagem de equações estruturais. Foram testados modelos com relações direta e mediacionais entre as variáveis. Os resultados indicam que a percepção de mudança medeia a relação entre o clima organizacional e a satisfação do cliente, que o clima organizacional possui uma relação direta com a satisfação do cliente e os empregados percebem mudanças relacionadas à gestão do clima organizacional.
\end{abstract}

Palavras-chave: clima organizacional, percepção de mudança, satisfação do cliente

\section{Relationship between Organizational Climate, Perception of Organizational Change and Customer Satisfaction}

\begin{abstract}
This study examines the relationships between organizational climate, perceptions of change and customer satisfaction in 170 units of a public service organization with operations throughout Brazil. Primary and secondary data were aggregated at the unit level using the technique of structural equation modeling. Models were tested with mediational and direct relationship between the variables. The results indicate that the perception of change mediates the relationship between organizational climate and customer satisfaction, the organizational climate has a direct relationship to customer satisfaction and employees perceive changes related to the organizational climate management.
\end{abstract}

Keywords: organizational climate, perception of change, customer satisfaction

Segundo Marchetti e Prado (2001), a satisfação das necessidades do cliente é um dos objetivos centrais das organizações na atualidade, razão pela qual muitos estudos têm sido desenvolvidos nessa área. No processo de satisfazer o cliente, as organizações voltam suas atenções para os membros que trabalham e prestam serviços com o propósito de concretizar sua missão e atingir os resultados desejados.

Assim, o clima organizacional tem se mostrado útil para contextualizar esse domínio, pois o entendimento de como as experiências de membros de um grupo são compartilhadas e como essas experiências influenciam as percepções, as cognições, os comportamentos e o desempenho do grupo é um tema importante a ser estudado (Lindell \& Brandt, 2000).

Por ser um instrumento de diagnóstico dos fatores relevantes na vida da organização, a pesquisa de clima organizacional é uma ferramenta muito utilizada para o planejamento de estratégias de gestão de pessoas visando à melhoria no ambiente de trabalho. Entretanto, a pesquisa é

1 Este trabalho é resultado da dissertação de mestrado da primeira autora, no Programa de Pós-graduação em Psicologia Social, do Trabalho e das Organizações da Universidade de Brasília - UnB.

2 Endereço para correspondência: Instituto de Psicologia, Universidade de Brasília, Campus Universitário Darcy Ribeiro, Instituto Central de Ciências Sul. Brasília, DF. CEP 70 910-900. E-mail: julianabsn@gmail.com apenas uma das etapas da gestão de clima organizacional. Para haver uma gestão do clima, é importante que mudanças sejam realizadas a partir do diagnóstico e, ao mesmo tempo, que os trabalhadores percebam as modificações implantadas.

Assim sendo, surgiu o interesse em examinar a relação existente entre clima organizacional, percepção de mudança organizacional e satisfação do cliente no presente estudo. De acordo com Karlof (1999), cliente refere-se ao consumidor assíduo e regular de produtos ou serviços oferecidos pela organização.

As percepções sobre o clima organizacional podem influenciar, entre outras variáveis, o comprometimento, a satisfação no trabalho, o absenteísmo e a rotatividade, que, segundo Koys e DeCotiis (1991), seriam chamados consequentes do clima. Neste trabalho, foi escolhido como consequente de clima a satisfação do cliente com o atendimento prestado, pois, durante o processo de atendimento, o cliente entra em contato direto com o trabalhador que, em última instância, supõe-se, está influenciado pelas características do ambiente de trabalho em que está inserido.

Schulte, Shmulyian, Ostroff e Kinicki (2009) estudaram a relação entre as dimensões do clima organizacional e o resultado organizacional satisfação do cliente no nível da unidade. Nesse estudo encontraram uma relação entre as duas variáveis. A relação entre clima organizacional e satisfação do cliente tem sido estudada principalmente em organizações 
prestadoras de serviços, uma vez que nesse processo existe uma interação entre os clientes e os funcionários (Bateson \& Hoffman, 2001). Assim, espera-se que um clima organizacional favorável traga reflexos positivos para os clientes que, certamente, percebem esse resultado.

Existem algumas suposições que sustentam essa hipótese. Em primeiro lugar, assume-se que uma organização prestadora de serviços é um sistema aberto que interage, influencia e é influenciada pelo segmento da sociedade na qual ela existe. Então, o modo como os empregados comportam-se em relação aos clientes deve ser resultado do clima de trabalho, ou seja, os empregados criam o clima que os clientes percebem (Schneider, 1973). Além disso, os clientes usam como base para formular as suas percepções os comportamentos e eventos específicos observados nas organizações com as quais eles se relacionam.

De acordo com Schneider (1973), organizações prestadoras de serviços são caracterizadas pela relação empregadocliente com um contato face a face. Ainda segundo o autor, os clientes possuem percepções sobre as organizações que têm base nas percepções de determinados comportamentos e eventos relacionados ao serviço específico.

Schneider, White e Paul (1998) estudaram a relação existente entre o clima organizacional e a satisfação do cliente. Os autores buscaram identificar antecedentes na organização que promovam um clima positivo para os empregados e consequentemente produzam comportamentos positivos neles perante os clientes.

Diante disso, este estudo tem como objetivo geral identificar a relação existente entre clima organizacional, percepção de mudanças decorrentes da pesquisa de clima, percepção de mudança na unidade e na organização e a satisfação do cliente com o atendimento prestado. Neste estudo, a expressão unidade refere-se a um ponto de atendimento ao cliente com estrutura administrativa específica (instalações, gestores, colaboradores, recursos tecnológicos etc.).

Essa lógica apoia-se no princípio de que a gestão do clima organizacional se caracteriza quando a organização apresenta mudanças que sejam percebidas pelos seus empregados, decorrentes de um diagnóstico feito a partir de uma Pesquisa de Clima Organizacional. Por consequência, a percepção positiva sobre as melhorias implantadas na empresa pode ser passada para o cliente durante o processo de interação, com reflexos na qualidade do atendimento prestado.

Assim, foi delineado o modelo de investigação representado na Figura 1, o qual prevê que o clima organizacional e a percepção de mudança decorrente da pesquisa de clima organizacional são preditores de satisfação do cliente. Portanto, a variável dependente do estudo é a satisfação do cliente e as variáveis independentes são o clima organizacional, a percepção de mudança decorrente da pesquisa de clima organizacional e a percepção de mudança na unidade e na organização.

A satisfação do cliente foi definida como a resposta dada pelo cliente sobre os serviços prestados no processo de atendimento, resultante da comparação da avaliação percebida do atendimento prestado em relação a suas expectativas. $\mathrm{O}$ clima organizacional é o resultado das percepções coletivas e compartilhadas dos empregados sobre o seu ambiente de trabalho e sobre a qualidade do relacionamento entre as pessoas, criadas mediante sua experiência durante o processo de trabalho.

A percepção de mudança decorrente da pesquisa de clima organizacional é a percepção de qualquer alteração planejada em componentes da organização, decorrente do diagnóstico realizado com base na pesquisa de clima organizacional, que traz alguma consequência, positiva ou negativa, para os resultados organizacionais ou para sua sobrevivência. Enquanto isso, a percepção de mudança na unidade e na organização caracteriza-se pela percepção da alteração da organização como um todo, diferenciando-se das alterações que foram motivadas pelos resultados da pesquisa de clima organizacional (Neiva, 2004).

Schneider (1973) afirma que o modo como os empregados comportam-se em relação aos clientes deve ser resultado do clima de trabalho da organização, ou seja, os empregados criam o clima que os clientes percebem. Essa assertiva é complementada por Salanova, Agut e Peiró (2005), ao afirmarem que a qualidade do serviço depende da qualidade existente na interação entre os empregados e os clientes. Bateson e Hoffman (2001) destacaram que no processo de prestação de serviços, com o atendimento, existe uma interação entre clientes e trabalhadores das organizações. Assim, pode-se supor que os clientes percebem, por meio dessa interação, o clima organizacional de determinada organização. Diversos estudos em organizações prestadoras de serviços têm dado suporte a essa afirmativa (Dietz, Pugh, \& Wiley, 2004; Johnson, 1996; Schneider, Ehrhart, Mayer, Saltz, \& Niles-Jolly, 2005; Schneider \& White, 2004; Schneider, et al., 1998).

Assim, são propostas as hipóteses para o presente estudo. A primeira afirma que o clima organizacional influencia diretamente a satisfação do cliente. Desse modo, as mudanças são essenciais no processo de gestão, pois, sem elas, o ciclo não se completa (De Sordi, 2005; Melo, 2009). As mudanças podem não ter o efeito esperado se os empregados não perceberem as melhorias implantadas pela empresa. Se os empregados percebem as melhorias implantadas pela empresa em decorrência de um diagnóstico realizado mediante pesquisa de clima organizacional, pode-se dizer que existe uma gestão de clima organizacional. Estas suposições deram origem à segunda hipótese do estudo, ou seja, a percepção

Gestão do Clima Organizacional

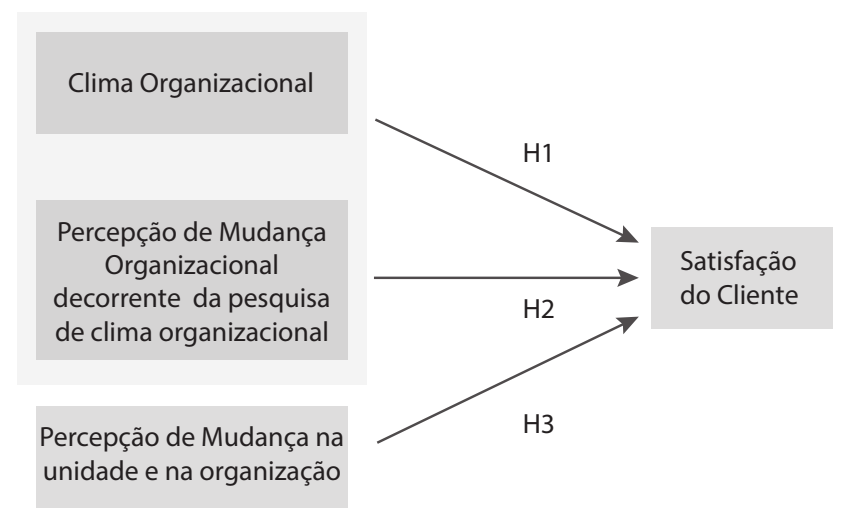

Figura 1. Hipóteses do estudo. 
de mudança decorrente da pesquisa de clima organizacional influencia diretamente a satisfação do cliente.

Além das mudanças realizadas em decorrência dos resultados da pesquisa de clima organizacional, concretizando assim a gestão, existem mudanças que foram realizadas pela empresa independentemente da gestão do clima organizacional. Essas mudanças também foram medidas e serão relacionadas com a satisfação do cliente, conforme a terceira hipótese, que afirma a influência direta da percepção de mudança na satisfação do cliente.

A Figura 1 ilustra as hipóteses do estudo e as respectivas relações do modelo a que se referem.

Dependendo do teor da mudança, a influência na satisfação do cliente pode ser negativa ou positiva, ou seja, o tipo de mudança realizada na organização pode ter uma influência tanto positiva quanto negativa na percepção dos clientes.

\section{Método}

\section{Amostra}

Foram analisadas 170 unidades de uma empresa pública prestadora de serviços, com sede no Distrito Federal, distribuídas em 22 estados da federação e Distrito Federal (AC, AL, AM, AP, BA, DF, CE, ES, GO, MG, MS, MT, PA, PB, PI, PR, RJ, RN, RR, RS, SC, SE e SP), totalizando 5.363 respondentes, entre empregados e clientes, sendo 2.013 empregados e 3.350 clientes.

\section{Procedimento}

Foram aplicados três instrumentos. Um de satisfação do cliente, outro de clima organizacional e um de percepção de mudança. O instrumento de satisfação do cliente foi aplicado em dois momentos. A primeira parte da aplicação foi realizada no momento em que o cliente entrava na unidade de atendimento (pré-atendimento), com o foco em avaliar a percepção inicial e as expectativas em relação ao atendimento. A escala contava com 17 itens que mediram as expectativas dos clientes, com uma escala variando de 1 (pior nota) a 10 (melhor nota). A segunda parte foi realizada após o mesmo cliente entrevistado no pré-atendimento ser atendido (pós-atendimento), com o foco em avaliar a percepção final e avaliação da experiência durante o atendimento. A escala aplicada nesse momento foi a mesma aplicada anteriormente. Os questionários respondidos pelos clientes foram agregados no nível das unidades de atendimento.

A escala de clima organizacional contava com 44 itens, configurados como afirmativas, que ofereceram ao respondente uma escala de respostas de 5 pontos, do tipo Likert, variando de 1. Discordo totalmente a 5. Concordo totalmente.

Com o objetivo de medir a percepção das mudanças ocorridas por influência dos resultados das pesquisas de clima organizacional e das mudanças realizadas pela empresa que não estavam vinculadas à gestão do clima organizacional,
Tabela 1. Índice de Correlação Intraclasse (ICC), Variância de erro e Variância de grupo das variáveis do modelo.

\begin{tabular}{lccc}
\hline Variáveis do modelo & ICC & $\begin{array}{c}\text { Variância } \\
\text { de erro } \\
\text { (within) }\end{array}$ & $\begin{array}{c}\text { Variância } \\
\text { de grupo } \\
\text { (between) }\end{array}$ \\
\hline Satisfação do Cliente & 0,35 & 0,815 & 0,454 \\
Atuação da Chefia & 0,19 & 0,734 & 0,176 \\
Imagem da Empresa & 0,10 & 0,406 & 0,046 \\
Práticas de Recursos Humanos & 0,10 & 0,698 & 0,077 \\
Condições de Trabalho & 0,15 & 0,724 & 0,124 \\
Relacionamento entre Colegas & 0,11 & 0,51 & 0,062 \\
\hline
\end{tabular}

foi aplicada uma escala de 17 itens sobre a percepção de mudança decorrente da pesquisa de clima organizacional.

Os itens foram apresentados aos respondentes com uma escala de cinco pontos, variando de 1 - Nada a 5 - Totalmente. Ao final do instrumento, foram apresentados dois itens gerais de percepção de mudança. No total, 1.520 empregados lotados nas mesmas unidades onde foram realizadas as pesquisas de clima organizacional e de satisfação do cliente responderam ao questionário de percepção de mudanças, os quais foram agregados nas 170 unidades de atendimento já mencionadas.

Após a realização das três pesquisas, cada banco de dados obtido recebeu os tratamentos necessários de preparação para as análises estatísticas. Depois disso, foi realizada a análise fatorial dos instrumentos de clima organizacional e satisfação do cliente.

Como os dados foram colhidos de respondentes diferentes (empregados e clientes), eles foram agregados pela média no nível da unidade. O próximo passo foi juntar todos os três bancos de dados em apenas um e assim foi possível a realização das análises multivariadas. As variáveis do modelo foram definidas no nível de análise da unidade para que pudesse ser feito o teste das relações.

A agregação dos dados justifica-se em função dos diferentes tipos de respondentes. Para comprovar empiricamente a adequação dessa agregação, foi calculado o Índice de Correlação Intraclasse (ICC), que corresponde à medida da proporção da variância atribuível a cada macrovariável. De acordo com James (1982), o índice de correlação intraclasse mede a extensão com que as unidades podem ser diferentemente confiáveis em termos de escores de dimensão individual.

O cálculo do ICC foi realizado por meio do programa estatístico SPSS versão 16.0. A Tabela 1 mostra os índices obtidos e os valores das análises de variância within e between. Apesar de não haver um rigoroso critério de aceitação para o índice de correlação intraclasse, James (1982) relata uma média de ICC no valor de 0,12 na literatura organizacional.

Todos os valores encontrados neste estudo giram em torno do valor sugerido por James (1982), com exceção do valor encontrado para a satisfação do cliente, que ficou um pouco acima. Apesar disso, os valores foram moderados para essa estatística, não existindo assim, proibição para que os dados fossem agregados. 


\section{Análise dos dados}

Foram realizadas análises descritivas e inferenciais dos dados, por meio da utilização do programa estatístico SPSS versão 16.0. A análise de adequação geral do modelo foi realizada por meio da técnica de modelagem de equações estruturais, por meio do programa estatístico AMOS, versão 7.0.

A modelagem de equações estruturais, segundo Hair, Anderson, Tatham e Black (2005), engloba diversas técnicas e todas são distinguidas por duas características: estimação de múltiplas relações de dependência e a habilidade para representar conceitos não observados nessas relações e explicar o erro de mensuração no processo de estimação.

\section{Resultados}

Foram realizadas análises descritivas dos dados de satisfação do cliente, clima organizacional e percepção de mudança. A Tabela 2 mostra o alfa de Cronbach, a média e o desvio padrão dos fatores de satisfação do cliente, clima organizacional e percepção de mudança.

Os índices de satisfação do cliente estão negativos devido ao cálculo realizado para encontrar a medida de satisfação (média da avaliação subtraída da média das expectativas). Isso significa dizer que a avaliação realizada pelos clientes do atendimento prestado pelas agências foi inferior às expectativas antes do atendimento, caracterizando uma insatisfação dos clientes.

O fator de satisfação do cliente que apresentou valor de média mais elevado foi Condições da Agência $(\mathrm{M}=-0,72)$, seguido de Satisfação Geral dos Clientes $(\mathrm{M}=-0,68)$ e de Atributos dos Atendentes $(\mathrm{M}=-0,58)$, como demonstram os resultados apresentados na Tabela 2 , ou seja, as expectativas mais elevadas e que não foram totalmente atendidas estão relacionadas com as condições da agência.
A análise dos valores de média nos respectivos fatores de clima organizacional mostrou que as respostas dos participantes se concentraram, em geral, acima do ponto médio da escala, com um baixo índice de dispersão. Os fatores de clima organizacional que apresentam médias (M) mais elevadas foram Atuação da Chefia $(\mathrm{M}=3,89)$, Relacionamento entre colegas $(\mathrm{M}=3,87)$, Imagem da empresa $(\mathrm{M}=3,72)$, seguidos da Prática de Recursos Humanos $(\mathrm{M}=3,47)$ e Condições de Trabalho $(\mathrm{M}=3,20)$. A análise da percepção de mudança mostrou que as respostas dos participantes se concentraram, em geral, um pouco acima do ponto médio da escala, com um baixo desvio padrão.

O fator Percepção de Mudança decorrente da pesquisa de clima organizacional foi o que obteve a maior média ( $\mathrm{M}=$ 3,05 ), seguido dos itens "o quanto a empresa mudou nos últimos dois anos" $(\mathrm{M}=2,94) \mathrm{e}$ "o quanto a unidade mudou nos últimos dois anos" $(\mathrm{M}=2,91)$.

Com o intuito de testar o modelo inicialmente proposto, analisou-se sua estrutura empírica por meio da técnica de modelagem de equação estrutural. Essa técnica exige que o modelo tenha um ajuste aos dados empíricos acima de 0,90 (Byrne, 2001). Para o teste de ajuste do modelo, foram considerados os seguintes índices: $\mathrm{X}^{2}$; CFI (Comparative Fit Index); RMSEA (Root Mean Square Error of Aproximation); NFI (Normed Fit Index); e GFI (Goodness-of-fit Index), conforme mostrado na literatura (Bentler, 1990; Byrne, 2001; Kline, 1998).

Adotaram-se como critérios de ajuste satisfatório de modelo aos dados, os seguintes valores dos índices: CFI superior a 0,90 ; RMSEA igual ou inferior a 0,08 ; GFI superior a 0,90 ; e NFI superior a 0,90 .

O modelo inicialmente proposto neste estudo apresentou índices de ajuste abaixo dos indicadores adotados. Assim, foram propostas algumas alterações para novos testes de ajuste do modelo. Essas alterações culminaram em dois outros modelos.

Tabela 2. Alpha de Cronbach, Média e Desvio Padrão dos fatores de satisfação do cliente, clima organizacional e percepção de mudança

\begin{tabular}{lllll}
\hline \multirow{2}{*}{$\begin{array}{l}\text { Construto } \\
\text { Satisfação do }\end{array}$} & Condições da Agência & $\begin{array}{l}\text { Alpha de } \\
\text { Cronbach }\end{array}$ & Média & $\begin{array}{l}\text { Desvio } \\
\text { Padrão }\end{array}$ \\
\hline Cliente & Atributos dos Atendentes & 0,875 & $-0,72$ & 0,75 \\
& Satisfação Geral dos Clientes & - & $-0,58$ & 0,66 \\
& Atuação da chefia & 0,962 & $-0,68$ & 0,70 \\
\hline \multirow{2}{*}{$\begin{array}{l}\text { Clima Organiza- } \\
\text { cional }\end{array}$} & Práticas de Recursos Humanos & 0,896 & 3,89 & 0,54 \\
& Condições de Trabalho & 0,830 & 3,72 & 0,34 \\
& Relacionamento entre colegas & 0,851 & 3,20 & 0,44 \\
& Percepção de Mudança decor- & - & 3,87 & 0,37 \\
\hline \multirow{2}{*}{$\begin{array}{l}\text { Percepção de } \\
\text { Mudança }\end{array}$} & $\begin{array}{l}\text { O quanto a unidade mudou nos } \\
\text { últimos 2 anos }\end{array}$ & - & 3,05 & 0,53 \\
& $\begin{array}{l}\text { O quanto a empresa mudou nos } \\
\text { últimos 2 anos }\end{array}$ & - & 2,91 & 0,66 \\
\hline
\end{tabular}




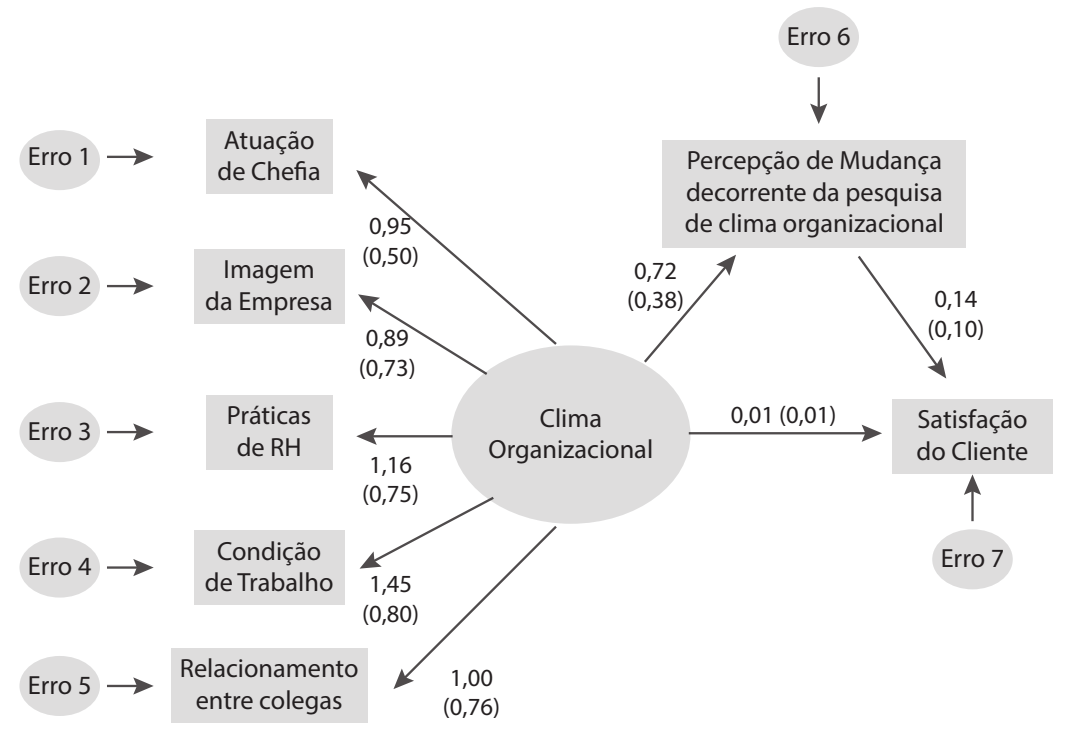

Figura 2. Pesos de regressão não-padronizados e padronizados do modelo.

O primeiro modelo propõe uma relação direta entre o clima organizacional e a satisfação do cliente e uma relação de mediação da percepção de mudança decorrente da pesquisa de clima organizacional entre o clima e a satisfação do cliente. Este pode ser observado na Figura 2.

O segundo modelo, que está na Figura 3, também propõe uma relação direta entre o clima organizacional e a satisfação do cliente e uma relação de moderação da percepção sobre o quanto mudou a unidade e a empresa entre o clima e a satisfação do cliente. Depois de definidos, os dois modelos foram submetidos a testes de ajustes. Os modelos 1 e 2 não apresentaram problemas de ajuste para um nível de significância $p<0,001$. A Tabela 3 mostra que todos os índices atingiram o critério de ajuste. As hipóteses inicialmente propostas no estudo foram testadas nos modelos ajustados. Porém, devido à reformulação do modelo foi preciso acrescentar a hipótese 1a: a relação entre o clima organizacional e a satisfação do cliente é mediada pela percepção de mudança.

A mediação foi acrescentada ao modelo, pois esta é uma relação mais aprofundada. Segundo Abbad e Torres (2002), o conceito de mediação implica suposição de relacionamentos entre as variáveis envolvidas. Dessa forma, tenta-se comprovar nos modelos reformulados o relacionamento entre as três variáveis do estudo - clima organizacional, percepção de mudança e satisfação do cliente.

Para o teste das hipóteses, foram analisados os pesos de regressão não padronizados (B) e padronizados (Beta) estimados pelos modelos. As Figuras 2 e 3 mostram os pesos de regressão não padronizados estimados e, entre parênteses, os pesos padronizados estimados para cada relação dos modelos 1 e 2 .

Tabela 3. Índices de ajustes dos modelos testados

\begin{tabular}{llllll}
\hline Modelo & Chi-quadrado & GFI & CFI & NFI & RMSEA \\
\hline Modelo 1 & $20,7(\mathrm{GL}=13)$ & 0,965 & 0,977 & 0,942 & 0,059 \\
Modelo 2 & $29,4(\mathrm{GL}=18)$ & 0,957 & 0,975 & 0,940 & 0,061 \\
\hline
\end{tabular}

Com base nos resultados apresentados na Figura 2, a hipótese 1 do estudo foi corroborada, pois observa-se que o clima organizacional influencia diretamente a satisfação do cliente. Porém, essa relação é fraca com um B e um Beta de 0,01 . A relação se fortalece com a mediação da percepção de mudança decorrente da pesquisa de clima organizacional.

Uma nova relação foi criada nesse modelo, a relação entre o clima organizacional e a satisfação do cliente com a mediação da percepção de mudança. Os resultados mostram que, quando a relação entre o clima organizacional e a satisfação do cliente é mediada pela percepção de mudança decorrente da pesquisa de clima organizacional, os pesos da regressão aumentam. Isto significa dizer que foi encontrada uma mediação pura e os empregados percebem a gestão do clima organizacional e esta gestão influencia diretamente a satisfação do cliente.

A relação entre o clima organizacional e a percepção de mudança decorrente da pesquisa de clima obteve o B da regressão igual a 0,72 e um Beta de 0,38. Isso demonstra uma relação entre as variáveis.

Pode-se considerar que a segunda hipótese do estudo foi aceita, pois os pesos da regressão mostram uma relação moderada, positiva e direta entre a percepção de mudança decorrente da pesquisa de clima organizacional e a satisfação do cliente.

Por fim, a percepção de mudança da terceira hipótese foi obtida sobre duas questões que visavam medir a percepção e mudança independentemente da pesquisa de clima organizacional. A primeira buscou identificar o quanto a unidade mudou nos últimos dois anos e a segunda o quanto a empresa mudou nos últimos dois anos. A Figura 3 mostra que a relação entre a percepção de mudança e a satisfação do cliente influencia diretamente a percepção do cliente, corroborando assim a hipótese 3 .

Porém, esta é uma relação negativa e, portanto, inversa, com índices B e Beta iguais a - 0,01 , ou seja, quanto maior é a percepção de mudança dos empregados, menor é a satisfação do cliente ou quanto menor é a percepção de mudança dos empregados, maior é a satisfação do cliente. 


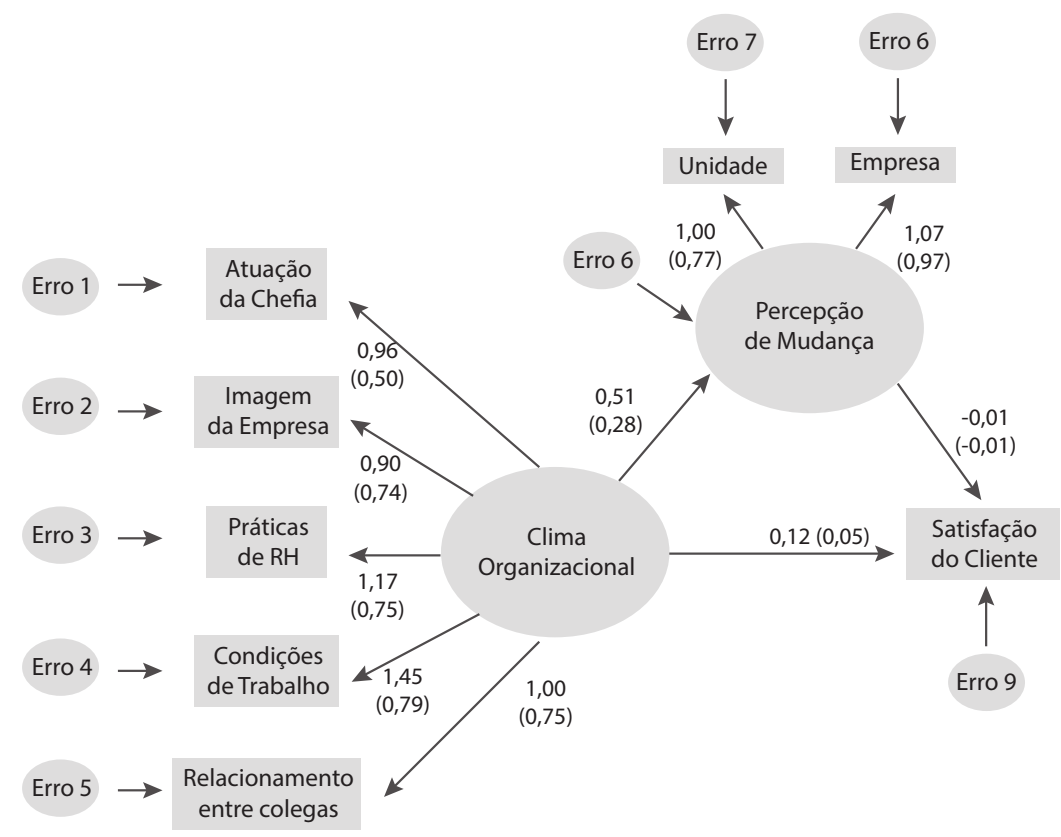

Figura 3. Pesos de regressão não-padronizados e padronizados do modelo 2

Os resultados obtidos do modelo 2 mostram uma relação mais forte entre o clima organizacional e a satisfação do cliente do que no modelo 1 , com um B de 0,12 e Beta de 0,05 , confirmando também a hipótese 1 . A relação entre o clima organizacional e a percepção de mudança mostrou-se forte, com B igual a 0,51 e Beta igual a 0,28.

Resumindo, as três hipóteses do estudo foram corroboradas, ou seja, o clima organizacional influencia a satisfação do cliente com a mediação da percepção de mudança decorrente da pesquisa de clima organizacional, a percepção de mudança decorrente da pesquisa de clima organizacional influencia diretamente a satisfação do cliente e a percepção de mudança geral influencia diretamente a satisfação do cliente. A seguir, será feita a discussão desses resultados à luz do referencial teórico.

\section{Discussão}

Os resultados encontrados corresponderam às expectativas iniciais do trabalho. Após a análise fatorial do instrumento de clima organizacional, foram encontrados cinco fatores com boa consistência interna que compõem o clima organizacional das unidades da empresa. Ao buscar uma base teórica do construto, verificou-se que os fatores encontrados são similares a outros encontrados na literatura nacional (Martins, Oliveira, Silva, Pereira, \& Sousa, 2004).

Puente-Palacios (2002) e Puente-Palacios e Freitas (2006) relatam que é de suma importância a necessidade de melhor compreensão e definição dos elementos que compõem o clima organizacional, já que este exerce influência sobre o comportamento e o desempenho dos membros, refletindo na efetividade da organização.

Com os resultados, descobriu-se que o fator Relacionamento entre colegas possui uma média alta $(\mathrm{M}=3,87)$, o que mostra sua importância na definição do construto. Esse resultado vai ao encontro da pesquisa qualitativa realizada por Neves (2008), na qual foi encontrada uma classe denominada Relacionamentos, que explicou $64 \%$ das entrevistas.

O fator Atuação da Chefia $(\mathrm{M}=3,89)$ foi o que obteve a maior média entre os cinco fatores. Vários estudiosos preocupam-se com o impacto da atuação da chefia no clima organizacional. Kozlowski e Doherty (1989) conduziram uma pesquisa, na qual os resultados mostraram que os indivíduos que apresentaram avaliações mais positivas da relação com seus supervisores tiveram percepções mais positivas do clima organizacional e demonstraram maior consenso e similaridade em suas percepções do que os indivíduos que relataram más relações com os supervisores. Dunegan, Tierney e Duchon (1992) verificaram em seu estudo que a categoria relacionada à qualidade das relações com o supervisor foi impactante para o clima organizacional, sendo preditora de cinco dos seis fatores do clima organizacional definidos para a pesquisa.

Com o intuito de verificar a relação existente entre as variáveis do estudo, desenvolveu-se um modelo de pesquisa. Um modelo é uma representação resumida e parcimoniosa da realidade que permite seu exame de maneira ampla, facilitando a identificação de padrões e relações, outrora distantes da percepção do pesquisador (Miles \& Shevlin, 2001).

Segundo Pasquali (2003), os modelos teóricos são construídos dedutivamente e precisam ser testados empiricamente para fornecerem um critério de verdade condizente com seu "sistema de saber", como aponta a ciência. No presente estudo, o modelo inicialmente proposto não obteve um ajuste satisfatório. Porém, os outros dois modelos criados com base no modelo inicial, obtiveram excelentes ajustes, o que mostra uma confiança nas relações estabelecidas no modelo (Byrne, 2001).

A primeira relação questionada foi entre o clima organizacional e a satisfação do cliente, que se refere à primeira hipótese do estudo. A hipótese apresentada afirma que existe uma relação direta entre o clima organizacional e a satisfação do cliente. Essa relação foi comprovada nos dois modelos apresentados. 
Por meio dos modelos testados, descobriu-se que a relação entre clima organizacional e satisfação do cliente apresenta maior ajuste do modelo quando é mediada pela percepção de mudança, principalmente mudanças decorrentes dos resultados da pesquisa de clima organizacional, como é esperado em um modelo mediacional. Na presença das duas variáveis (a mediadora e a independente), há uma redução da relação direta entre as variáveis independente e dependente.

Segundo Abbad e Torres (2002, p. 21): "o conceito de mediação implica suposição de relacionamentos entre as variáveis envolvidas. Uma variável mediadora é aquela que, ao estar presente na equação de regressão, diminui a magnitude do relacionamento entre uma variável independente e uma variável dependente".

Vieira (2009) confirma que a inserção da mediação na equação estrutural neutraliza ou reduz a força do impacto da variável independente sobre a dependente, conforme aconteceu no presente estudo.

Alguns estudos encontrados na literatura tentaram relacionar o clima organizacional com a satisfação do cliente. Porém, a maioria dos estudos que tentou fazer essa relação testou as relações do clima organizacional com a qualidade dos serviços prestados e não com a satisfação do cliente (Davidson, 2003; Johnson, 1996; Schneider et al., 1998). Este estudo amplia o escopo dos anteriores e testa a relação com a satisfação do cliente.

A segunda hipótese da pesquisa afirma que a percepção de mudança decorrente da pesquisa de clima organizacional influencia diretamente a satisfação do cliente. Os resultados encontrados no Modelo 1 mostraram existir uma relação direta entre a percepção de mudança decorrente da pesquisa de clima organizacional e a satisfação do cliente, ou seja, os empregados percebem que existe na empresa uma gestão de clima organizacional e essa gestão influencia a satisfação do cliente.

Segundo De Sordi (2005), o termo "gestão" compreende algumas fases como: planejamento, projeto, construção, implementação, utilização, monitoramento, identificação de melhorias e realização de ajustes. Portanto, para que exista uma gestão, é preciso que todas as etapas do ciclo sejam cumpridas. Quando os empregados percebem as mudanças realizadas de acordo com o planejamento, pode-se dizer que realmente existe uma gestão.

Alinhado com essa visão, Melo (2009) apresenta um modelo de gestão do clima organizacional que contempla quatro fases: 1) Planejamento e realização da pesquisa; 2) Análise dos dados e divulgação dos resultados; 3) Elaboração e implantação dos planos de ação de melhoria; e 4) Avaliação. Portanto, é o desenvolvimento completo do ciclo de gestão que poderá resultar em benefícios para o aprimoramento das relações de trabalho na organização.

Além de mudanças que são realizadas a partir de um planejamento e uma gestão de clima organizacional, existem outras mudanças que são feitas na empresa. Estas mudanças também foram medidas nesta pesquisa e relacionadas com a satisfação do cliente.

$\mathrm{O}$ dado encontrado por esta pesquisa respalda as especulações teóricas sobre a necessidade da gestão do clima organizacional, o que remete a uma implicação prática dos resultados desta pesquisa.
A última hipótese diz que a percepção de mudança influencia diretamente a satisfação do cliente. Os resultados obtidos com o Modelo 2 mostraram que existe uma relação inversa das mudanças mais gerais realizadas na empresa com a satisfação do cliente, ou seja, quanto maior a percepção de mudança do trabalhador, menor é a satisfação do cliente.

Assim, os dados revelaram que, quando a mudança é planejada dentro das ações de melhorias da gestão de clima organizacional, esta se relaciona direta e positivamente com a satisfação do cliente. Entretanto, quando as mudanças são mais gerais e não envolvem a gestão do clima organizacional, esta se torna uma relação indireta e negativa. Isso pode ser explicado pelo escopo das mudanças realizadas na empresa nos últimos dois anos.

A presente pesquisa traz diversas contribuições ao estudo do clima organizacional, percepção de mudança e satisfação do cliente. $\mathrm{O}$ trabalho apresentou uma ferramenta que possibilita medir a gestão de clima organizacional por meio da percepção dos empregados sobre mudanças implantadas pela empresa, caracterizando um avanço na área de gestão empresarial.

Dessa forma, o estudo comprovou a importância de serem realizadas regularmente pesquisas de clima organizacional, com o objetivo de diagnosticar e identificar aspectos que necessitam de melhorias e, a partir daí, implementar mudanças com foco nas melhorias.

O estudo constitui-se de um avanço no estudo da percepção de mudança. Apenas implementar mudanças não significa que será obtido o efeito esperado. É necessário saber se os empregados percebem que foram implantadas mudanças, pois é esta percepção que pode afetar a satisfação do cliente. De maneira geral, o estudo corrobora os achados de outros autores que utilizam a percepção de mudanças como medida de mudanças na organização (Domingos, 2009; Mauro, 2008; Neiva, 2004).

O método utilizado neste trabalho também constitui um avanço em estudos científicos no Brasil. Esta pesquisa conseguiu uma variabilidade no nível da unidade com agências de diversos estados da federação. A técnica de agregar os dados mostrou-se adequada com o objetivo proposto, pois, no nível da unidade, foi possível estudar a relação entre dois tipos de respondentes: o empregado e o cliente.

A pesquisa mostrou a importância do estudo da satisfação do cliente. Os resultados mostraram que tanto o clima organizacional quanto a percepção de mudança impactam a satisfação do cliente. Na satisfação do cliente, estão envolvidas as expectativas e estas podem ser determinantes na satisfação final do cliente com o atendimento prestado. Os resultados deste trabalho trazem um importante questionamento sobre o cálculo da satisfação final do cliente.

\section{Conclusões}

Este trabalho procurou testar as diversas relações existentes entre o clima organizacional, a percepção de mudança e a satisfação do cliente. Apesar das limitações metodológicas do estudo, considera-se que o presente trabalho atingiu seus objetivos principais e apontou importantes implicações práticas, teóricas e metodológicas. 
A literatura consultada evidencia a existência de um clima organizacional agradável para a obtenção de bons desempenhos, interações positivas e produtivas, satisfação dos clientes, tanto internos quanto externos, em um processo dinâmico e contínuo de estruturação com práticas organizacionais. Isso foi corroborado no presente trabalho e a técnica utilizada foi de grande valia para a obtenção de dados consistentes.

Um aspecto encontrado foi a importância do fator "Relacionamento entre colegas". Isso mostra que as organizações devem se preocupar com o relacionamento do empregado com outros empregados, no tocante ao compartilhamento de informações, integração, respeito e comprometimento com resultados.

Este trabalho mostrou a importância e efetividade de uma gestão de clima organizacional. Mostrou também a importância de se fazer uma avaliação da percepção de mudança. Além disso, o estudo evidenciou que a gestão do clima organizacional produz alterações na organização que influenciam a satisfação do cliente. Portanto, o gerenciamento das mudanças, ou seja, a forma como o gestor irá lidar com a mudança, é uma questão que precisa ser valorizada em uma empresa. Assim, pode-se tentar amenizar resistências que podem vir a ocorrer com os empregados.

Por fim, por meio dos dados encontrados neste trabalho pode-se fazer diversas recomendações à empresa. Esta pesquisa possui material para a elaboração e execução de estratégias visando ao crescimento e desenvolvimento da empresa. $\mathrm{O}$ estudo mostrou que uma gestão completa e adequada de clima organizacional influencia positivamente a satisfação do cliente. Por isso, deve-se pensar em meios para melhorar o clima organizacional.

Com o intuito de melhorar o clima organizacional da unidade, recomenda-se que sejam adotadas ações no sentido de promover a capacitação dos gestores para uma maior integração com suas equipes de trabalho.

Em relação ao desenvolvimento de futuras pesquisas, tais como a desenvolvida neste trabalho, recomenda-se sua replicação em outras empresas com o objetivo de confirmar as relações aqui encontradas.

\section{Referências}

Abbad, G., \& Torres, C. V. (2002). Regressão múltipla stepwise e hierárquica em psicologia organizacional: aplicações, problemas e soluções. Estudos em Psicologia, 7, 19-29.

Bateson, J. E. G, \& Hoffman, K. D. (2001). Marketing de Serviços (L. Simonini, Trad.) São Paulo: Bookman.

Bentler, P. M. (1990). Comparative fit indexes in structural models. Psychological Bulletin, 107, 238-246.

Byrne, B. M. (2001). Structural equation modeling with Amos: Basic concepts, applications and programming. New Jersey: Lawrence Erlbaum Associates.

Davidson, M. C. G. (2003). Does organizational climate add to service quality in hotels? International Journal of Contemporary Hospitality Management, 15(4/5), 206-213.

De Sordi, J. O. (2005). Gestão por processos: uma abordagem da moderna administração. São Paulo: Saraiva.
Dietz, J., Pugh, S. D., \& Wiley, J. W. (2004). Service climate effects on customer attitudes: An examination of boundary conditions. Academy of Management Journal, 47, 81-92.

Domingos, S. G. (2009). Influência dos Fatores de Capacidade Organizacional na Percepção de Mudanças. Dissertação de mestrado, Universidade de Brasília, Brasília.

Dunegan, K., Tierney, P., \& Duchon, D. (1992). Perceptions of an innovate climate: examining the role of divisional affiliation, work group interaction, and leader/subordinate exchange. IEE Transaction of Engineering management, 39(3), 227-236.

Hair, J. F.; Anderson, R. E.; Tatham, R. L., \& Black, W. C. (2005). Análise Multivariada de Dados (A. S. Sant'Anna \& A. C. Neto, Trad.). Porto Alegre: Bookman.

James, L. (1982). Aggregation bias in estimates of perceptual agreement. Journal of Applied Psychology, 76, 214-224.

Johnson, J. (1996). Linking employee perceptions of service climate to customer satisfaction. Personnel Psychology, 49, 831-851.

Karlof, B. (1999). Conceitos básicos de administração: um guia conciso (S. D. Schiros, Trad.). Rio de Janeiro: Rocco.

Kline, R. B. (1998). Principles and practices of structural equation modeling. New York: Guilford Press.

Koys, D., \& DeCotiis, T. (1991). Inductive measures of psychological climate. Human Relations, 44(3), 265-285.

Kozlowski, S., \& Doherty, M. (1989). Integration of climate and leadership: examination of a neglected issue. Journal of Applied Psychology, 74(4), 546-553.

Lindell, M. K., \& Brandt, C. J. (2000). Climate Quality and Climate Consensus as Mediators of the Relationship Between Organizational Antecedents and Outcomes. Journal of Applied Psychology, 85(3), 331-348.

Marchetti, R. \& Prado, P. H. M. (2001). Um tour pelas medidas de satisfação do consumidor. Revista de Administração de Empresas, 41(4), 56-67.

Martins, M. C. F., Oliveira, B., Silva, C. F., Pereira, K. C., \& Sousa, M. R. (2004). Construção e validação de uma escala de medida de clima organizacional. Psicologia: Organizações e Trabalho, 4(1), 37-60.

Mauro, T. G. S (2008). Mudança Organizacional Radical e Institucionalismo: Teste Empírico de Modelo para Transformação Organizacional. Dissertação de mestrado, Universidade de Brasília, Brasília.

Melo, E. A. A. (2009). Gestão do Clima Organizacional. In J. P. Barros Neto (Ed.), Administração de Organizações Completas: liderando e simplificando a gestão para criar valor e maximizar resultados (pp. 176-205). Rio de Janeiro: Qualitymark,.

Miles, J. \& Shevlin, M. (2001). Applying regression and correlation: a guide for students and researchers. London: Sage Publications.

Neiva, E. R. (2004). Percepção de mudança individual e organizacional: o papel das atitudes e das características organizacionais. Tese de doutorado, Universidade de Brasília, Brasília.

Neves, J. B. S. (2008, julho). Clima Organizacional: uma revisão do construto. Trabalho apresentado no III Congresso Brasileiro de Psicologia Organizacional e do Trabalho, Florianópolis, Santa Catarina.

Pasquali, L. (2003). Psicometria. Teoria dos testes na psicologia e na educação. Petrópolis: Vozes. 
Puente-Palacios, K. E. (2002). Abordagens teóricas e dimensões empíricas do conceito de clima organizacional. Revista de Administração, 37(3), 96-104.

Puente-Palacios, K. E. \& Freitas, I. A. (2006). Clima organizacional: uma análise de sua definição e de seus componentes. Revista Organizações e Sociedade, 13(38), 45-57.

Salanova, M., Agut, S. \& Peiró, J. M. (2005). Linking Organizational Resources and Work Engagement to Employee Performance and Customer Loyalty: The Mediation of Service Climate. Journal of Applied Psychology, 90(6), 1217-1227.

Schneider, B., Ehrhart, M. G., Mayer, D. M, Saltz, J. L., NilesJolly, K (2005). Understanding organization-customer links in service settings. Academy of Management Journal, 48(6), 1017-1032.

Schneider, B. (1973). The Perception of Organizational Climate: The customer's view. Journal of Applied Psychology, 57(3), 248-256.

Schneider, B., White, S. S., \& Paul, M. C. (1998). Linking service climate and customer perceptions of service quality: test of a causal model. Journal of Applied Psychology, 83, 462-469.
Schneider, B., \& White, S. S. (2004). Service quality: Research perspectives. Thousand Oaks: Sage.

Schulte, M., Shmulyian, S., Ostroff, C., \& Kinicki, A. (2009). Organizational Climate Configurations: Relationships to Collective Attitudes, Customer Satisfaction, and Financial Performance. Journal of Applied Psychology, 94(3), 618-634.

Vieira, V. A. (2009). Moderação, mediação, moderadora-mediadora e efeitos indiretos em modelagem de equações estruturais: uma aplicação no modelo de desconfirmação de expectativas. Revista de Administração da Universidade de São Paulo, 44(1), 17-33.

Recebido em 23.09.2010

Primeira decisão editorial em 29.02.2012

Versão final em 11.05.2012

Aceito em 30.01.2013 